\title{
Akt and mTORC1 signaling as predictive biomarkers for the EGFR antibody nimotuzumab in glioblastoma
}

\author{
Michael W. Ronellenfitsch ${ }^{1,2,3^{*}}$ (D), Pia S. Zeiner ${ }^{1,2,3,4}$, Michel Mittelbronn ${ }^{4,5,6,7}$, Hans Urban ${ }^{1,2,3}$, Torsten Pietsch ${ }^{8}$, \\ Dirk Reuter ${ }^{9}$, Christian Senft ${ }^{10}$, Joachim P. Steinbach ${ }^{1,2,3}$, Manfred Westphal ${ }^{11}$ and Patrick N. Harter ${ }^{2,3,4^{*}}$ (D)
}

\begin{abstract}
Glioblastoma (GB) is the most frequent primary brain tumor in adults with a dismal prognosis despite aggressive treatment including surgical resection, radiotherapy and chemotherapy with the alkylating agent temozolomide. Thus far, the successful implementation of the concept of targeted therapy where a drug targets a selective alteration in cancer cells was mainly limited to model diseases with identified genetic drivers. One of the most commonly altered oncogenic drivers of GB and therefore plausible therapeutic target is the epidermal growth factor receptor (EGFR). Trials targeting this signaling cascade, however, have been negative, including the phase III OSAG 101-BSA-05 trial. This highlights the need for further patient selection to identify subgroups of GB with true EGFR-dependency. In this retrospective analysis of treatment-naive samples of the OSAG 101-BSA-05 trial cohort, we identify the EGFR signaling activity markers phosphorylated PRAS40 and phosphorylated ribosomal protein S6 as predictive markers for treatment efficacy of the EGFR-blocking antibody nimotuzumab in MGMT promoter unmethylated GBs. Considering the total trial population irrespective of MGMT status, a clear trend towards a survival benefit from nimotuzumab was already detectable when tumors had above median levels of phosphorylated ribosomal protein S6. These results could constitute a basis for further investigations of nimotuzumab or other EGFR- and downstream signaling inhibitors in selected patient cohorts using the reported criteria as candidate predictive biomarkers.
\end{abstract}

Keywords: Epidermal growth factor receptor, Mammalian target of rapamycin, Glioblastoma, Nimotuzumab, Biomarker, Targeted therapy

\section{Introduction}

Glioblastoma (GB) is an incurable brain cancer and the most common primary brain tumor in adults [33]. The epidermal growth factor receptor (EGFR) is frequently genetically altered in GB by gene amplification and mutations including a variant where deletion of exons 2-7 causes activated signaling termed EGFRvIII. EGFR gene alterations can be found in $45.1 \%$ of GBs [32], mutations in members of the receptor tyrosine kinase- Ras-PI3 Kinase-AKT signaling network are the most frequent

\footnotetext{
* Correspondence: M.Ronellenfitsch@gmx.net; patrick.harter@kgu.de ${ }^{1}$ Dr. Senckenberg Institute of Neurooncology, University Hospital Frankfurt, Goethe University, Schleusenweg 2-16, 60528 Frankfurt am Main, Germany ${ }^{2}$ German Cancer Consortium (DKTK), Partner Site Frankfurt/Mainz, Frankfurt am Main, Germany

Full list of author information is available at the end of the article
}

mutations (87.9\% of cases) in GB [32]. Further, EGFR signaling is known to enhance proliferative signaling, resistance to cell death and reprogramming of energy metabolism [13, 38, 45]. Therefore, EGFR is a plausible target in GB therapy. Several clinical trials have been performed, with however rather disappointing results [39]. Strategies targeting EGFR in GB include small molecule inhibitors (e.g. erlotinib), antibodies or antibody-drug conjugates (e.g. depatuxizumab mafodotin (ABT-414)) as well as novel immunooncological approaches like a vaccine against EGFR $v I I I$ with rindopepimut. The depatuxizumab antibody portion of ABT-414 preferentially binds to cells with amplified EGFR or EGFRvIII [35]. After binding ABT-414 is internalized and can block microtubule formation via its mafodotin part [51]. Currently larger phase II and III clinical trials are underway evaluating ABT-414 
in the primary (Intellance 1 phase III trial, ClinicalTrials.gov NCT02573324) and recurrent disease (Intellance 2 phase II trial, ClinicalTrials.gov NCT02343406) setting. In the ACT IV trial, the EGFRvIII vaccine rindopepimut did not prolong survival in GB patients [53]. It is noteworthy that the EGFRvIII mutation if present usually is only found in a fraction of tumor cells within a GB [54] and that even during the course of standard treatment EGFR$v I I I$ is frequently lost [53]. Standard treatment for patients in sufficient clinical condition has been established in 2005 already and involves surgical resection, radiotherapy and chemotherapy with the alkylating agent temozolomide which led to median overall survival times of 14.6 months [47]. Many trials have been conducted in recent years, however, no new drugs have been approved [27, 39]. Histologically, GB is characterized by marked hypoxic areas, with typical histological features of neoangiogenesis and necrosis in a diffusely infiltrating growing glial tumor [25]. These areas reflect the metabolically challenging microenvironment where nutrient and oxygen supply can frequently not match demand of the tumor cells. The transcription factor hypoxia-inducible factor $1 \alpha$ (HIF-1 $\alpha)$ is a major cellular regulator of adaptive programs to hypoxia and stabilization occurs when oxygen is low [42].

The current WHO classification further stratifies GB as either isocitrate dehydrohgenase (IDH) wildtype (wt) or IDH mutant (mut). The vast majority of primary GB harbors IDH wt status [24]. Further, current treatment relevant molecular stratification of GB mainly depends on the methylation status of the $\mathrm{O}(6)$-methylguanine methyltransferase (MGMT)-promoter. MGMT-promoter methylation correlates with reduced expression of the DNA repair enzyme MGMT. Consequently, tumors with methylated MGMT promoter generally respond better to temozolomide treatment whereas MGMT expression in tumors with unmethylated gene promoter is a major mechanism of resistance and indicator for poor prognosis $[15,16,46]$.

Many novel approaches to improve GB therapy rely on targeting specifically altered signal transduction cascades. However, these so called targeted therapies, including those targeting EGFR, thus far, have failed to show any benefit in GB treatment despite rational target selection and availability of potent drugs opening the quest for predictive biomarkers $[39,52]$. One important downstream mediator of EGFR signaling is the kinase Akt (Fig. 1a) with numerous phosphorylation targets involved in proliferation, survival, cell motility and angiogenesis [49]. Proline rich Akt substrate of $40 \mathrm{kDa}$ (PRAS40) has been identified as an inhibitory component of mTOR complex 1 (mTORC1). Akt is the main regulator of phosphorylation at Thr246 and relieves PRAS40-mediated inhibition of mTORC1 (Fig. 1a) [23,
41]. PRAS40-phosphorylation correlated with shorter time to progression in a smaller GB patient cohort [8]. Another study in low grade glioma found a trend towards shorter survival in tumors with higher phospho-PRAS40 levels; however, statistical significance was not reached [29]. Besides its regulation via PRAS40 phosphorylation, Akt also activates mTORC1 via inhibitory phosphorylation of a protein complex consisting of tuberin (TSC1), hamartin (TSC2) as well as the more recently discovered TBC1D7 (this complex will be termed in TSC1/2 in the following text for simplicity reasons) (Fig. 1a) [10, 19]. MTORC1 additionally integrates signals from the cellular energy status including oxygen availability [4], amino acid availability [2] and direct ATP content of the cell [20]. The ribosomal protein S6 (RPS6) is a downstream effector of mTORC1 and is part of the ribosomal machinery. RPS6 phosphorylation has been discovered many years ago, still its molecular and physiological effects especially with regard to the phosphorylation of the different serine sites are currently still under investigation [31]. RPS6 has several mTORC1-dependent phosphorylation sites including serines at position 235 and 236 as well as the highly specific position 240 and 244 (Fig. 1a) [31, 34].

Nimotuzumab is a blocking monoclonal antibody against EGFR [48] without intrinsic EGFR activating activity. It has shown promising results as a targeted therapy in the treatment of high grade gliomas in phase II studies [3] and pediatric brain stem gliomas [28, 57]. Therefore, a two arm phase III clinical trial (OSAG 101-BSA-05) involving 149 patients was performed comparing standard (radiotherapy and temozolomide) treatment with and without addition of nimotuzumab (EudraCT No. 2005-003101-85, Clinical Trials.gov NCT00753246) [55]. Nimotuzumab was administered once weekly (400 $\mathrm{mg}$ ) during the concomitant radio-temozolomide phase and afterwards continued biweekly (400 mg) for 12 weeks during the adjuvant temozolomide treatment phase. The trial was negative, and a benefit of nimotuzumab treatment was apparent neither in the whole population studied nor in patients with EGFR amplification. A post-hoc analysis of subgroups, however, revealed a trend for improved survival for MGMT unmethylated patients with residual tumor when treated with nimotuzumab (PFS 6.2 vs. 4.0 months; OS 19.0 vs. 13.8 months). This unplanned subgroup analysis, however, included only 28 patients and failed to reach statistical significance. The results of several recent trials suggest that for an effective targeted therapy, appropriate patients need to be identified [56]. With regard to signal transduction inhibitors it is plausible that genetic heterogeneity in GBs is also reflected by different degrees of dependence on certain signaling cascades [32]. The aim of this study 


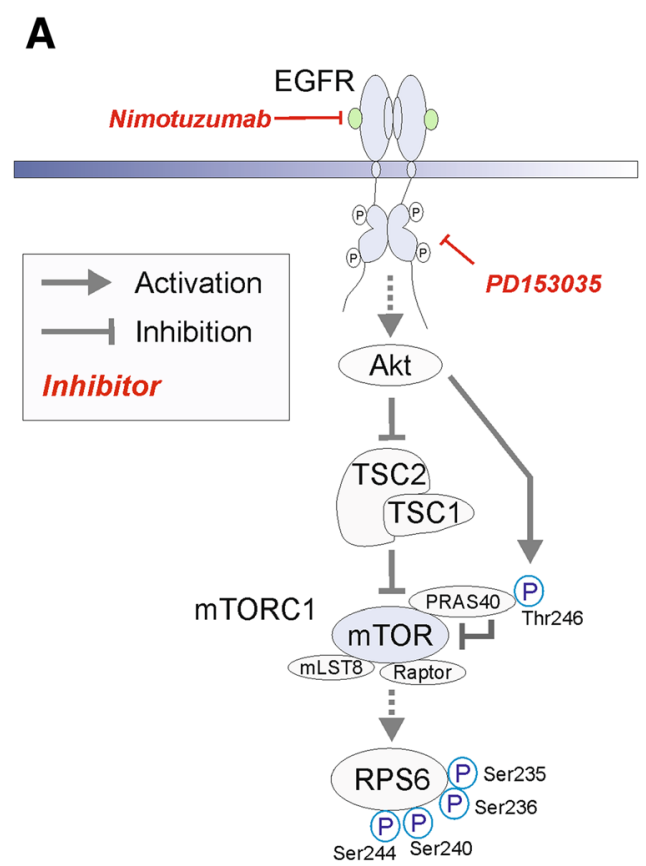

B

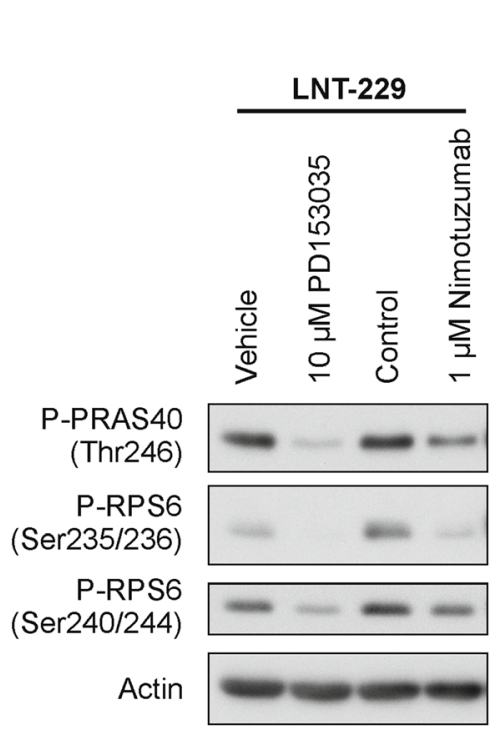

Fig. 1 EGFR signal transduction and effects of EGFR inhibition on downstream targets. a Scheme of EGFR signal transduction. Nimotuzumab and PD153035 are inhibitors of EGFR: Activation of EGFR results in activation of Akt signaling which relieves a TSC1/TSC2 as well as PRAS40 (via phosphorylation of Thr246) -mediated inhibition of mTORC1. RPS6 phosphorylation at Ser235/236 and Ser 240/244 is regulated by mTORC1. b LNT-229 cells were incubated in serum-free DMEM for 90 min with vehicle (DMSO control), PD153035 (dissolved in DMSO), control solution for nimotuzumab (placebo solution of the trial) or $1 \mu \mathrm{M}$ nimotuzumab as indicated. Cellular lysates were analyzed by immunoblot with antibodies as indicated

was to analyze EGFR-dependent Akt and mTORC1 signaling in treatment-naive tumor samples of the OSAG 101-BSA-05 patient cohort as a potential predictive biomarker of nimotuzumab efficacy. We analyzed the response to nimotuzumab therapy of molecular subgroups depending on activation of Akt and mTORC1 signaling, extent of necrosis, HIF- $1 \alpha$ staining and MGMT-methylation status. We here report a predictive signature of RPS6 and PRAS40 phosphorylation in MGMT unmethylated patients. Furthermore, we describe a trend for a predictive value of RPS6 phosphorylation in all patients irrespective of MGMT promoter methylation status.

\section{Materials and methods \\ Reagents}

Nimotuzumab as well as the corresponding placebo control solution were provided by Oncoscience (Wedel, Germany). Nimotuzumab is an IgG subtype 1 kappa with a molecular weight of $147.613 \mathrm{kDa}$. The EGFR inhibitor PD153035 [11] was purchased from Sigma Aldrich (Taufkirchen, Germany).

\section{Cell culture}

LNT-229 GB cells have been described previously $[38,50]$ and were maintained in Dulbecco's modified eagle medium
(DMEM) containing 10\% foetal calf serum (FCS) (Biochrom KG, Berlin, Germany), $100 \mathrm{IU} / \mathrm{ml}$ penicillin and $100 \mathrm{mg} / \mathrm{ml}$ streptomycin (Life Technologies, Darmstadt, Germany).

\section{Immunoblot}

Immunoblot was performed as described previously [14]. $10 \mu \mathrm{g}$ of protein per condition were used for SDS-PAGE analysis. Membranes were incubated with antibodies against phospho-RPS6 (Ser 240/244) (D68F8; Cell Signaling), phospho-RPS6 (Ser 235/236) (D57.2.2.E; Cell Signaling), phospho-PRAS40 (Thr246) (C77D7, Cell signaling) or actin (\# sc-1616 Santa Cruz Biotechnology, Dallas, Texas, USA). The secondary HRP-conjugated antibodies were purchased from Santa Cruz Biotechnology (Dallas, Texas, USA). A chemiluminescence solution was used for detection [50].

\section{Patients, sample collection and immunohistochemistry} The OSAG 101-BSA-05 study (EudraCT No. is 2005003101-85, ClinicalTrials.gov

NCT00753246) cohort included 149 patients with GB [55]. This open label, randomised phase III study was approved by the central and local ethics review boards. Informed consent was obtained from all patients. In case of availability, we obtained tissue sections from these 
tumors for further immunohistochemistry. We investigated the amount of necrosis (\%) in hematoxylin and eosin (HE)-stained slides of the tissue sections $(n=111)$, HIF- $1 \alpha$ expression (\%) in the vital tumor centre $(n=$ $106)$ as well as in perinecrotic areas $(n=98)$, P-PRAS40positive cells $(\%)(n=101)$, P-RPS6-positive cells $(\%)(n$ $=109)$ as well as Iba1-positive cells $(\%)(n=100)$ using standard procedures on an automated IHC staining system. Stainings with antibodies against threonine 246-phosphorylated PRAS40 (P-PRAS40) and serine 240/244-phosphorylated RPS6 (P-RPS6) (Cell signaling, \#2997 and \#5364 respectively) were performed as recently reported [14]. Furthermore, the following antibodies were used: HIF-1 $\alpha$ (Novus Biologicals, NB 100134), Iba1 (Wako, 019-19,741). Samples that consisted of $100 \%$ necrosis were excluded from further analysis.

\section{Statistical analyses}

Statistical analyses were performed using JMP version 13 software (SAS Institute, Heidelberg, Germany). A $p$-value of $p<0.05$ was chosen to declare statistical significance. Applied statistical test methods are either mentioned in the figure legend or in the flow content. For dichotomized univariate survival analyses we performed a median split to obtain a high and low group with regard to the investigated factor. The high group includes specimen with values above median, the low group includes specimen with median or below.

\section{Results}

\section{Nimotuzumab inhibits EGFR downstream signaling}

To test whether nimotuzumab inhibited signaling from the EGFR-downstream kinases Akt and mTORC1 (Fig. 1a), we exposed human LNT-229 glioblastoma cells to nimotuzumab or the intracellular EGFR inhibitor PD153035 [11]. Both substances caused effective inhibition of EGFR downstream signal transduction indicated by a similar degree of reduction in phosphorylation of the corresponding target proteins PRAS40 as well as RPS6 in an immunoblot experiment (Fig. 1b). We chose P-PRAS40 (Thr246) and P-RPS6 (Ser240/244) in our further tissue analysis due to the specificity of the phosphorylation site and the availability of robust, monoclonal antibodies for IHC. Effective Akt inhibition by nimotuzumab had also previously been reported in other cell lines including EGFR overexpressing U87 GB cells, lung and nasopharyngeal carcinoma cells $[7,18,37]$.

\section{Phosphorylation of PRAS40 and RPS6 is only detectable in a small proportion of tumor cells and does not correlate with EGFR gene amplification}

For histological characterization of our cohort, we evaluated the extent of necrosis, P-PRAS40, P-RPS6 and HIF- $1 \alpha$ in perinecrotic as well as in vital tumor areas.
Additionally, we analyzed Iba1 expression as a marker for glioma-associated microglia and macrophages (GAMs) and potential source of P-PRAS40 and P-RPS6 expression (Additional file 1: Figure S1). Extent of necrosis ranged from 0 to $100 \%$, with a median of $10 \%$ (Fig. 2a). HIF-1 $\alpha$ within central vital tumor areas was undetectable in most tumors but ranged up to $20 \%$ in one tumor with a median of $0 \%$ (Fig. $2 \mathrm{~b}$ ). In contrast, perinecrotic HIF- $1 \alpha$ ranged from 0 to $80 \%$ with a median of $10 \%$ (Fig. 2c) and correlated with necrosis extent (Additional file 2: Figure S2). P-PRAS40 was detectable in a fraction of cells with a range of 0 to $80 \%$ and a median of $10 \%$ (Fig. 2d). P-RPS6 was similarly detectable in a fraction of tumor cells with a similar range of 0 to $60 \%$ however the median was lower at 3\% (Fig. 2e). Besides the actual GB tumor cells, GAMs can account for a relevant fraction of intratumoral cells and potentially influence signal transduction of cancer cells or constitute a potential source of mTORC1 or AKT signaling. Therefore, we stained the samples for the pan-microglia and macrophage $(\mathrm{M} / \mathrm{M})$ marker Iba1. Staining frequency ranged from 3 to $70 \%$ with a median of $20 \%$ (Fig. 2f). Neither P-PRAS40 nor P-RPS6 correlated with Iba1 (Fig. 2g, h). In contrast, P-PRAS40 and P-RPS6 expression as markers of EGFR signal transduction correlated (Fig. 2i). Besides being downstream of EGFR, mTORC1 is also regulated by the cellular energy charge and nutrient supply $[20,40]$. GB necrosis occurs where demand exceeds supply of the fast growing tumor cells and the perinecrotic area is where nutrient and oxygen deprivation are most severe within the tumor. Interestingly, P-RPS6 as a target of mTORC1 was increased in necrotic tumors potentially indicating a defective nutrient sensing as a cause of increased necrosis [50] (Fig. 2j). An inverse correlation was found for P-PRAS40 (Fig. 2k). Neither P-PRAS40 nor P-RPS6 correlated with Hif- $1 \alpha$ staining (data not shown).

Information on EGFR amplification and vIII mutation was available for 88 and 81 cases respectively [55]. EGFR gene amplification correlates with increased expression of EGFR [43] and was found in 43 cases. An inverse effect was detectable on downstream Akt but not mTORC1 signal transduction (Fig. 2l). However, with only 7 cases of vIII mutation in our cohort, the number was too small to derive any conclusions in this regard. Notably, there was also no difference in the end points for patients with and without EGFR amplification or vIII mutation in the OSAG 101-BSA-05 trial [55].

\section{Necrosis extent and HIF-1a staining is not associated with patient survival}

While necrosis as a surrogate of hypoxia or ischemia is a common histological feature in GB, a more outspread or increased necrosis extent or hypoxia could indicate a 

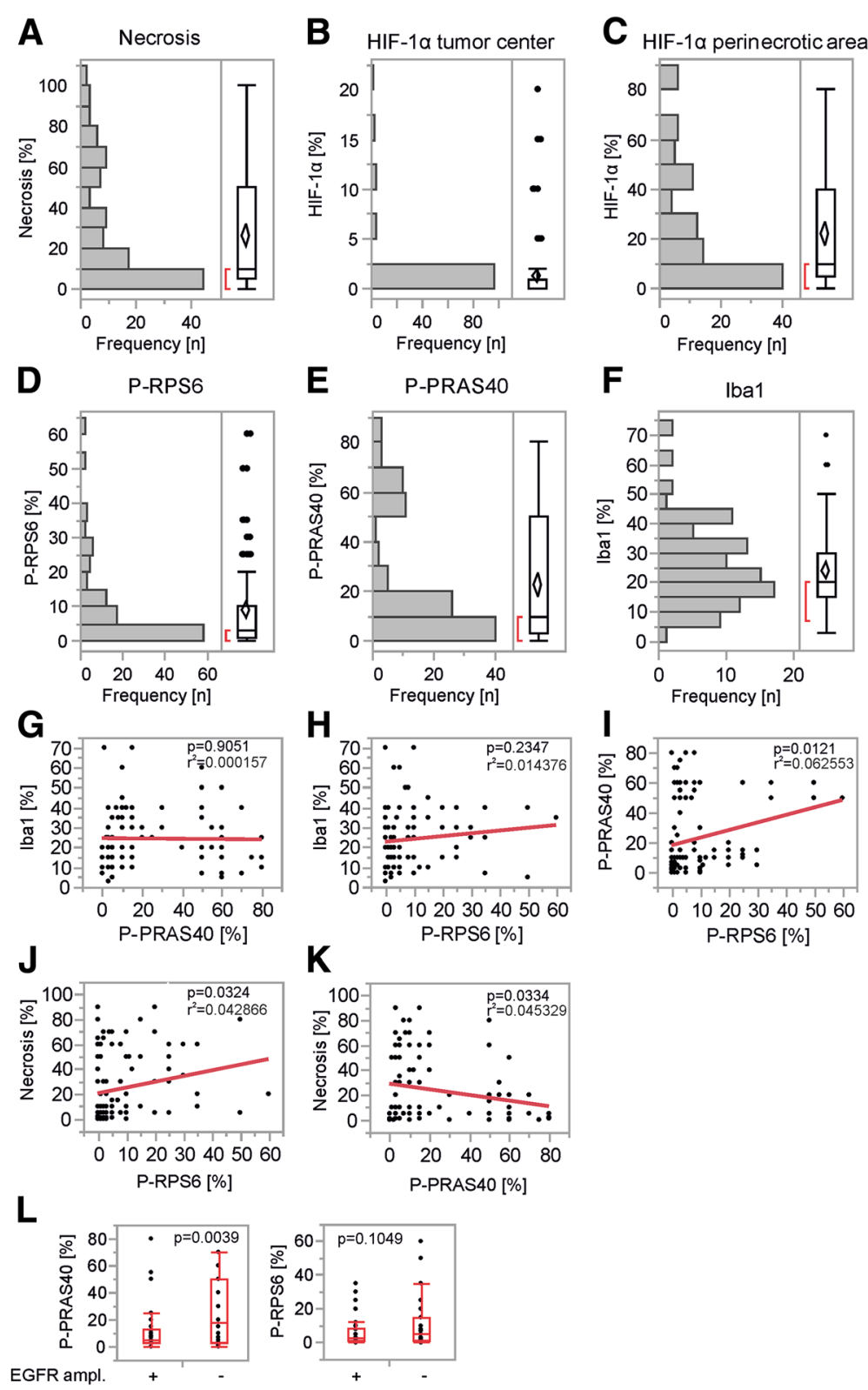

Fig. 2 Histological characterization of the patient cohort. a-f, outlier box plot for the distribution of necrosis, HIF-1a in vital, central or perinecrotic tumor areas, phosphorylated (P-)RPS6, P-PRAS40 and Iba1 in samples as indicated (horizontal line within the box is the median sample value; confidence diamond contains the mean and the upper and lower $95 \%$ of the mean; ends of the box represent the 25th and 75th quantiles; bracket outside of the box is the shortest half, which is the most dense $50 \%$ of observations). $\mathbf{g - k}$, correlations of histological markers as indicated in a bivariate plot with a linear regression analysis. P and $r^{2}$ values as indicated. I one way analysis with outlier box plot of P-PRAS40 and P-RPS6 in EGFR amplified vs. non-amplified tumor specimens. $P$-value calculated using Student's $t$-test

particularly aggressive tumor subtype. A relationship between patient survival and intratumoral hypoxia has e.g. been reported for uterine cancer [17]. In our cohort, we did not find an association between necrosis extent or HIF- $1 \alpha$ staining and patient survival in univariate Weibull parametric survival analysis (Table 1). EGFR signaling is known to promote many components of a more aggressive tumor phenotype and P-PRAS40 has been reported as an independent prognostic marker with regard to time to progression in a small glioma cohort [8]. Neither P-RPS6 nor P-PRAS40 staining correlated with overall survival (Table 1).

\section{Treatment of hypoxic tumors with nimotuzumab is not detrimental}

We have previously shown that inhibition of EGFR or mTORC1 signal transduction can protect human glioblastoma cells from hypoxia-induced cell death [38, 45]. 
Table 1 Correlation of histology markers with survival

\begin{tabular}{|c|c|c|c|c|c|c|}
\hline \multirow{2}{*}{$\begin{array}{l}\text { Treatment } \\
\text { arm }\end{array}$} & \multicolumn{6}{|c|}{ Parametric survival Weibull $p$} \\
\hline & Necrosis & HIF-1a perinecrotic area & HIF-1a vital tumor & P-PRAS40 & P-RPS6 & lba1 \\
\hline Nimotuzumab & 0.7360 & 0.3733 & 0.6135 & 0.2365 & 0.6078 & 0.5149 \\
\hline Control & 0.1003 & 0.4436 & 0.7257 & 0.6929 & 0.2967 & 0.0275 \\
\hline
\end{tabular}

Univariate Weibull parametric survival analysis was performed for the listed parameters

Therefore, we hypothesized that in tumors with increased necrosis or HIF- $1 \alpha$ staining, nimotuzumab could mediate tumor-protective effects resulting in decreased survival of patients. Necrosis extent, HIF-1 $\alpha$ staining, P-PRAS40, P-RPS6 and Iba1 staining were well-balanced between the two treatment arms (Additional file 3: Figure S3A). Using a median split, we dichotomized tumors into two groups (high and low) (Additional file 1: Figure S1). Within the group of above median value necrotic tumors, nimotuzumab treatment resulted in a slight trend towards improved survival, whereas no trend was detectable in below or median value necrotic tumors (Fig. 3a). Also, no trend was detectable with regard to HIF- $1 \alpha$ high and low tumors (Fig. 3b). Even though P-PRAS40 and P-RPS6 were not associated with patient survival in the treatment arms (Table $1)$, tumors with activated downstream signaling might define a patient subgroup more addicted to EGFR signaling and thus more prone to respond to nimotuzumab. There was no trend in overall survival in tumors with high or low P-PRAS40 with regard to nimotuzumab therapy (Fig. 3c). In contrast in P-RPS6 high tumors, we observed a clear trend towards improved survival when nimotuzumab treatment was administered (Fig. 3d).

Unmethylated MGMT promoter status defines a subgroup in which high necrosis, P-RPS6 or P-PRAS40 tumors benefit from nimotuzumab treatment

In accordance with previous results, MGMT promoter methylation status was associated with patient survival in the OSAG 101-BSA-05 study cohort [55]. To test if the difference in biological behavior was also reflected by different activities of Akt and mTORC1 signaling, we investigated P-PRAS40 and P-RPS6 in both tumor subgroups. There was no difference in staining frequency for P-PRAS40 and P-RPS6 in MGMT promoter methylated vs. unmethylated tumors (Additional file 3: Figure S3B). In MGMT unmethylated GBs a treatment effect might be to a lesser extent concealed by temozolomide efficacy. When considering only the MGMT unmethylated cohort, the clear trend in favor of nimotuzumab therapy already detectable in the whole cohort regardless of MGMT promoter methylation status, now became significant when using a median split for P-RPS6 in tumors with above median value ( $p$ value of 0.02 , Wilcoxon) (Fig. 4a). Additionally, the same effect was also detectable when using a P-PRAS40 median split in the
MGMT promoter unmethylated tumor cohort $(p=0.03$, Wilcoxon) (Fig. 4a). Also, there was a trend towards an efficacy of nimotuzumab in MGMT promoter unmethylated tumors with above median extent of necrosis (Fig. 4a). No effect was detectable in tumors with below or median values for necrosis, P-RPS6 and P-PRAS40 (Fig. 4b).

\section{P-RPS6 expression predicts survival depending on the treatment group in MGMT promoter unmethylated GBs}

We wondered whether P-RPS6 was also relevant for survival of patients within the treatment arms in MGMT promoter unmethylated GBs. In patients treated with nimotuzumab, an above median expression of P-RPS6 was associated with improved survival (Fig. 5a, left panel). In contrast in patients with control treatment, above median P-RPS6 expression was associated with reduced survival (Fig. 5a, right panel). No association of P-PRAS40 with patient survival within the treatment arms was detectable when using a median split (Fig. 5b).

Increased GAM levels correlate with improved survival in patients treated with nimotuzumab

GAMs constitute relevant portions of a GB and the assumption that GAMs might be associated with an adverse prognosis in GB patients is under debate [44]. Interestingly, in tumors with above median Iba1 staining frequency (Iba1 high), nimotuzumab treatment was associated with a prolonged survival (Fig. 6, right panel). In contrast no effect of nimotuzumab was detectable for tumors with below median Iba1 staining frequency (Iba1 low) (Fig. 6, left panel).

\section{Discussion}

The experience with targeted therapies in recent GB trials has been overall disappointing highlighting the need for predictive biomarkers. In this retrospective analysis of samples of the OSAG 101-BSA-05 trial [55], we investigated histological subgroups based on necrosis and hypoxia as markers for a nutrient-deprived tumor microenvironment as well as for phosphorylation of PRAS40 and RPS6 as downstream markers of EGFR signaling. We hypothesized a reduced efficacy of EGFR inhibition therapy in tumors with pronounced necrosis or hypoxia due to potential protective effects of inhibitor therapy in this context [38, 45]. Tumor hypoxia as indicated by HIF- $1 \alpha$ staining as well as necrosis were not associated 


\section{Necrosis}

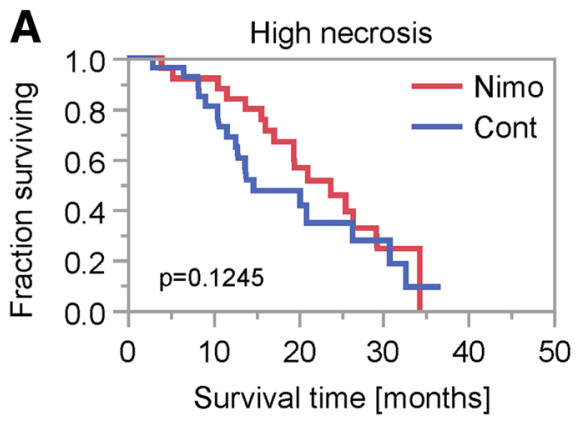

Low necrosis

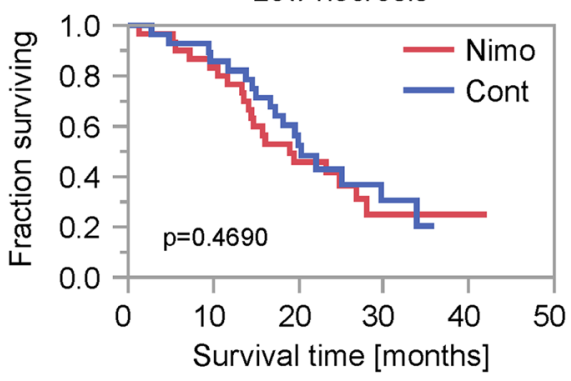

P-PRAS40
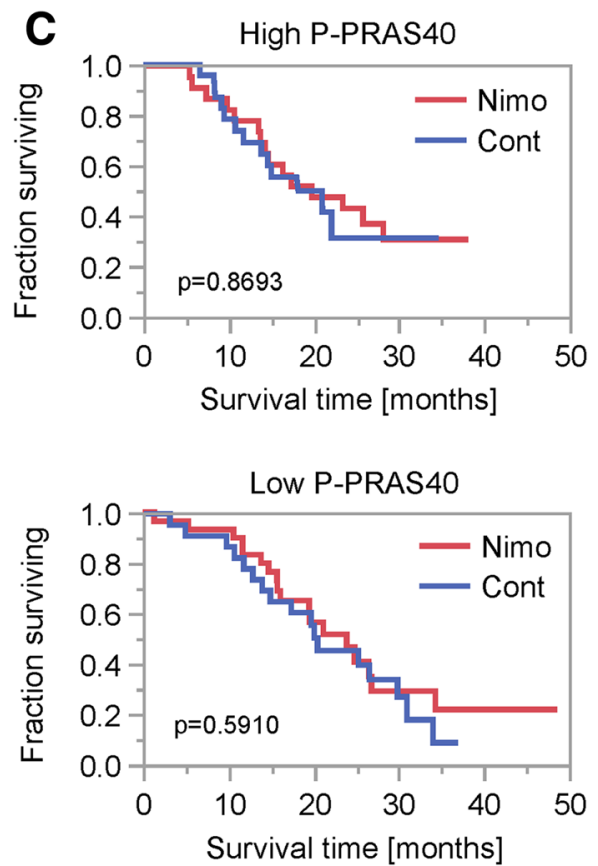

HIF-1 $\alpha$ perinecrotic area

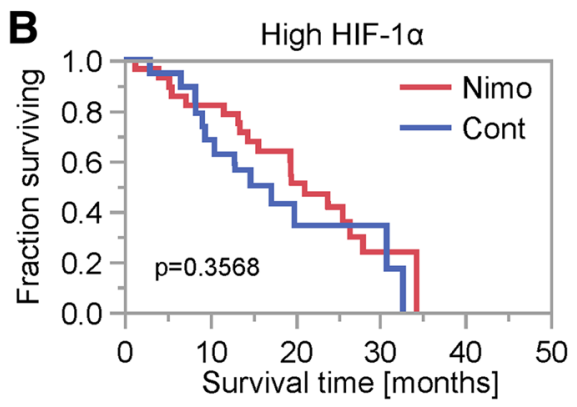

Low HIF-1a

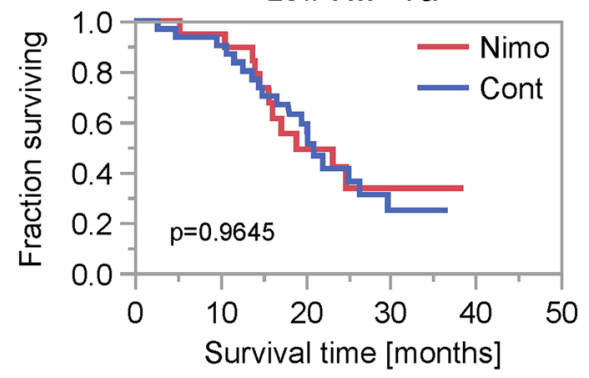

P-RPS6
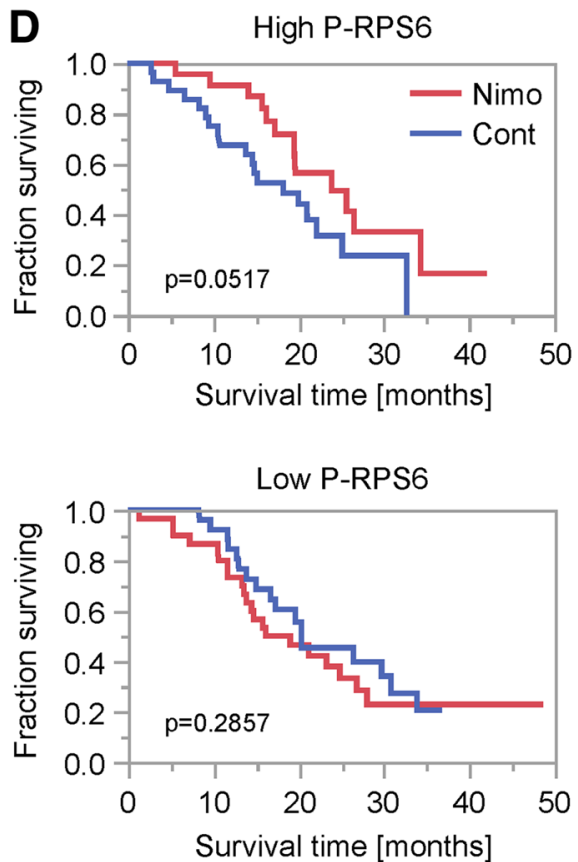

Fig. 3 Survival analyses depending on treatment in histological subgroups. a-d Kaplan-Meier survival curves for patients treated with nimotuzumab (nimo) or placebo (cont) in dichotomized histological subgroups (median split, above median: high, below and equal to median low) for necrosis (a), HIF-1a in perinecrotic regions (b), P-PRAS40 (c) and P-RPS6 (d). $P$ values were calculated using the Wilcoxon test 
A MGMT promoter unmethylated

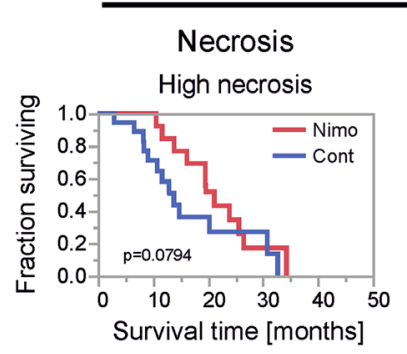

\section{P-RPS6}
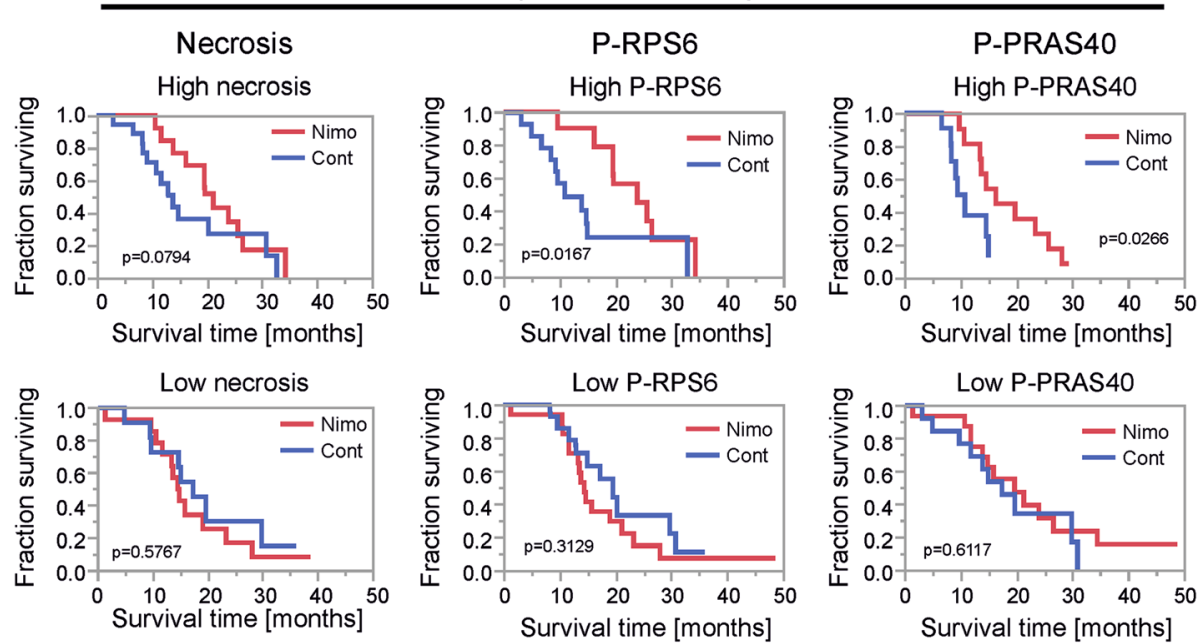

B

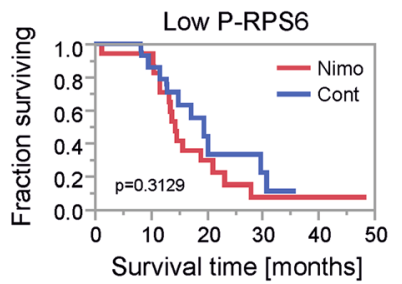

MGMT promoter methylated

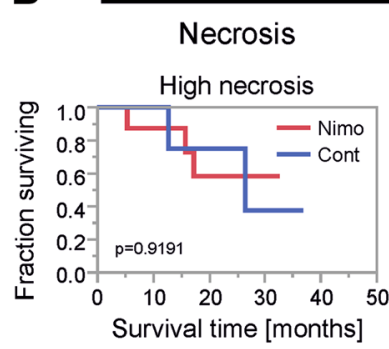

P-RPS6

P-PRAS40
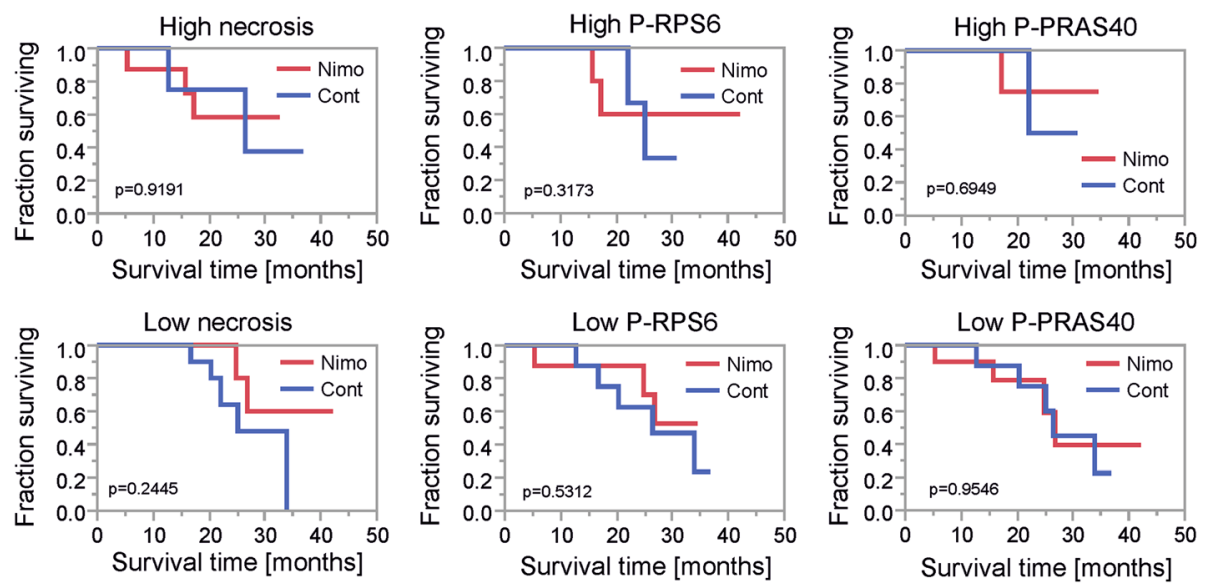

Fig. 4 Survival analyses depending on treatment in histological subgroups for the MGMT-promoter unmethylated and methylated tumor cohort. a-b Kaplan-Meier survival curves for patients treated with nimotuzumab (nimo) or placebo (cont) in dichotomized histological subgroups (median split, above median: high, below and equal to median low) for necrosis, P-PRAS40 and P-RPS6 in the MGMT-promoter unmethylated (a) and methylated (b) tumor cohort. P values were calculated using the Wilcoxon test

with patient survival (Table 1). When using a median split for necrosis extent, on the contrary to our hypothesis, there was a slight trend towards improved efficacy of nimotuzumab in patients with tumors with above median necrosis (Fig. 3a). No trend was detectable using a median split for perinecrotic HIF- $1 \alpha$ staining frequency (Fig. 3b). HIF-1 $\alpha$ staining frequency in vital tumor tissue was low with a median of $0 \%$, therefore we did not include a dichotomized analysis in our study. GBs with increased signaling from EGFR and downstream kinases might constitute a collective with oncogene addiction exposing an Achilles heel for targeted therapies. Dichotomizing for P-PRAS40 high and low tumors had no effect on nimotuzumab treatment efficacy (Fig. 3c), in contrast to P-RPS6 where a clear trend towards nimotuzumab efficacy was detectable in tumors with high P-RPS6 (Fig. 3d). Neither P-PRAS40 nor P-RPS6 was associated with patient survival (Table 1). However, when testing for time to progression, P-PRAS40 was associated with a shorter interval (Additional file 4: Figure S4A) similar to a previous report [8].

The majority of GB (approximately 55-65\%) has an unmethylated MGMT promoter defining a subgroup that is especially difficult to treat due to the reduced efficacy of temozolomide [9, 15, 22]. When investigating only MGMT unmethylated tumors, above median P-RPS6 was associated with nimotuzumab efficacy (Fig. 4a) which has already been detectable as a trend in the whole study cohort (Fig. 3a, d). In addition, above median P-PRAS40 was associated with improved survival in patients treated 
MGMT unmethylated P-RPS6 high vs. low
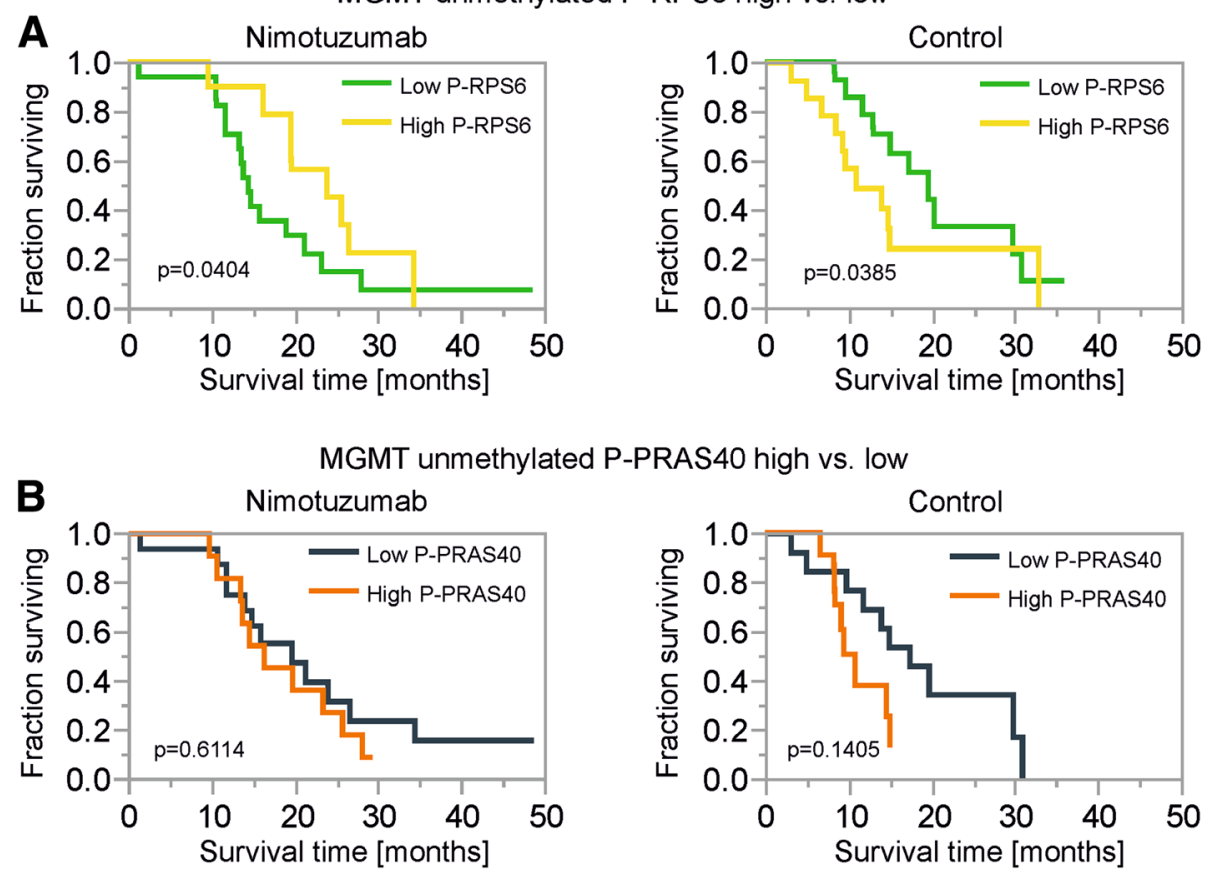

Fig. 5 Prognostic relevance of P-RPS6 and P-PRAS40 in treatment groups of MGMT-promoter unmethylated tumors. a-b Kaplan-Meier survival curves for patients with MGMT promoter unmethylated GBs treated with nimotuzumab or placebo (control) for dichotomized histological subgroups (median split, above median: high, below and equal to median low) for P-RPS6 (a) and P-PRAS40 (b). P values were calculated using the Wilcoxon test

with nimotuzumab (Fig. 4a). The positive correlation between necrosis extent and P-RPS6 (Fig. 2j) was unexpected considering that mTORC1 is also a component of central cellular nutrient sensing pathways and cells with intact nutrient sensing inhibit mTORC1 in nutrient deplete conditions [50]. This indicates a potentially dysregulated mTORC1 sensor in our cohort resulting in higher extent necrosis as has been suggested recently (Additional file 4: Figure S4B) [50]. The efficacy of nimotuzumab in patients with high P-RPS6 (as a trend in the whole study cohort and statistically significant only in MGMT unmethylated GBs) points to a potentially higher degree of addiction to mTORC1 and ultimately EGFR signaling in this subgroup. While the homogeneous patient cohort of a registered randomized phase III trial adhering to central monitoring standards was a major strength of our study, introducing subgroups naturally shrunk patient numbers and our results need to be

Treatment efficacy in Iba1 high vs. low
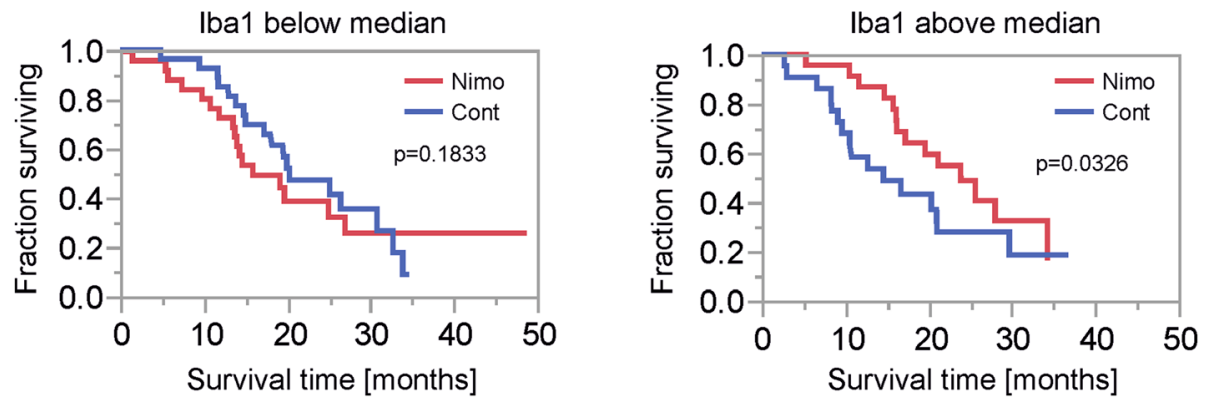

Fig. 6 Survival analysis depending on treatment in subgroups based on microglial prevalence. Kaplan-Meier survival curves for patients treated with nimotuzumab (nimo) or placebo (cont) in dichotomized subgroups based on lba1 staining frequency (median split, above median: high, below and equal to median low). P values were calculated using the Wilcoxon test 
validated prospectively in a larger patient cohort using our EGFR signaling markers as entry criteria. Additionally, PTEN and PI3 Kinase loss/mutation are frequent events in GB ( $\sim 36 \%$ and $\sim 6 \%$ of GB samples respectively) [32] and most likely partly impact nimotuzumab efficacy. Therefore, it is remarkable that P-RPS6 dichotomization was sufficient to define a subgroup with a clear trend towards nimotuzumab efficacy in samples of unknown PTEN and PI3 Kinase status (Fig. 3). In an upcoming prospective analysis, it would be important to include these markers and PTEN and PI3 Kinase wildtype status would most likely define an even more nimotuzumab-susceptible subgroup of tumors. Accordingly, in a previously published retrospective analysis of tissue of 26 GB patients treated with the non-antibody EGFR inhibitors erlotinib or gefitinib response in the recurrent disease setting correlated with expression of vIII-mutated EGFR and PTEN [30]. No evaluation of downstream phosphorylation events in the tumor tissue was included in this analysis, still these results suggest that tumors with high EGFR signaling activity and intact signal transduction are sensitive to EGFR inhibitors. In the recent phase II EORTC 26082 trial, similar to our results, mTORC1 activation as indicated by phosphorylation of the mTOR protein itself at Ser2448 was a marker to predict response to treatment with the mTOR inhibitor temsirolimus in MGMT unmethylated GBs [56]. The relevant kinase that mediates phosphorylation of mTOR at Ser2448 is S6 Kinase [5] which is exactly the same kinase that mediates RPS6 phosphorylation and therefore is responsible for P-RPS6 in our cohort (Additional file 4: Figure S4C). Additionally, in multivariate analyses, PRAS40 phosphorylation was associated with survival in the temsirolimus treatment arm [56]. The authors propose phosphorylated mTOR (Ser2448) and P-PRAS40 as potential biomarkers for mTOR inhibitor therapy in MGMT-promoter unmethylated GBs. Our results confirm this notion with nimotuzumab as an indirect mTORC1 inhibitor (Fig. 1b). Integrating the results of the analyses of predictive signatures for EGFR [30] and mTOR inhibitors [56] and our analysis points to a signature where a high (er) degree of activation and an intact EGFR signaling axis defines GBs susceptible to inhibitors of this pathway in general. Accurate analysis of the in vivo phosphorylation status of proteins by IHC to monitor EGFR signaling activity requires special caution. E.g. time to processing and several other factors can have a major influence on phosphorylation and dephosphorylation events [14]. Therefore, for a prospective analysis of biomarkers in a clinical trial, standardized tissue asservation will be an important topic to include in the protocol.

The need for and potential adverse effects of neglecting potential predictive biomarkers is highlighted by the recently published results of the thus far largest randomized phase II trial evaluating the efficacy of the mTORC1 inhibitor everolimus in newly diagnosed GB that randomized 171 patients [6]. Patients receiving everolimus in addition to standard radiochemotherapy in this trial had a reduced survival in comparison to sole standard radiochemotherapy $[1,6]$. One potential explanation of these results demonstrating reduced survival when an mTOR inhibitor was added to the therapeutic regimen in GB could be protective effects of mTOR inhibition in the context of the tumor microenvironment that we have previously shown in cell culture models [38].

Data regarding the prognostic impact of the innate immune system including GAMs in GBs is conflicting [12, $21]$. In our study cohort, we found a positive effect on prolonged overall survival in patients treated with nimotuzumab with GBs of above median Iba1 frequency (Fig. 6). Investigating the whole patient cohort irrespective of treatment arm, we found no association with survival when dichotomizing for high vs. low GAM infiltration (Additional file 4: Figure S4D). These results contrast the notion that GAM subpopulations might have negative effects on GB patient survival [36]. However, similar findings as in our cohort regarding the prognostic role of GAMs are described, likewise demonstrating a positive prognostic impact of at least a GAM subpopulation in GB [58]. Currently we can only speculate on the underlying reasons for this positive effect of intratumoral GAMs on overall survival in GB patients treated with nimotuzumab. It is interesting to note that microglia express receptors for binding of the Fc part of antibodies and might therefore react with nimotuzumab-bound GB cells similar to mechanistic hypotheses of antibody mediated plaque clearance in Alzheimer's models [26]. Further clarifying potential antibody effects on GAMs is beyond the scope of this article and should be investigated elsewhere.

\section{Conclusions}

The quest for new treatment options in GB has been cumbersome at best with no new drugs gaining approval since the introduction of temozolomide. In this current study, we investigated tissue samples of yet another negative phase III trial. The EGFR is one of the most plausible treatment targets in this cancer entity. We here report markers for the selection of patients that might benefit from the EGFR-blocking antibody nimotuzumab. Considering the majority of GB patients with unmethylated MGMT promoter status, activation of Akt or mTORC1 signaling was associated with a benefit from nimotuzumab treatment. A clear trend towards a benefit from nimotuzumab therapy was also detectable in the whole study cohort using activation of mTORC1 as a marker for dichotomy. We believe that our results constitute a basis for further investigation of nimotuzumab or other EGFR- and mTORinhibitors in selected patient cohorts using the reported criteria as candidate predictive biomarkers. 


\section{Additional files}

Additional file 1: Figure S1. Representative images of histological subclassifications. Representative images of immunohistochemical staining for HIF-1a, P-PRAS40, P-RPS6 and Iba1 from FFPE tumor specimens of below and equal to (low) and above (high) median marker frequency. (TIF $13094 \mathrm{~kb}$ )

Additional file 2: Figure S2. Correlation of perinecrotic HIF-1a and necrosis. Correlation of perinecrotic HIF-1a and necrosis in a bivariate plot with a linear regression analysis. P and $r^{2}$ values as indicated. (TIF $64 \mathrm{~kb}$ )

Additional file 3: Figure S3. Distribution of histology markers in treatment arms. A, one way analysis with outlier box plot of necrosis, HIF$1 a$ in perinecrotic or in vital central tumor regions, P-RPS6, P-PRAS40 and Iba1 in tumors of patients treated with nimotuzumab (nimo) or placebo (cont). B, one way analysis with outlier box plot of P-RPS6 and P-PRAS40 in tumors with methylated or unmethylated MGMT promoter. P-value calculated using Student's t-test. (TIF $495 \mathrm{~kb}$ )

Additional file 4: Figure S4. Survival analyses and schemes of signal transduction. A, Weibull parametric analysis of P-PRAS40 and time to progression in patients treated with nimotuzumab (left panel) or placebo (control, right panel). B, scheme of a nutrient sensing via mTORC1 and effects on cellular adaptation and necrosis. Cells with an intact mTORC1 sensor inhibit mTORC1 signaling during nutrient deprivation and hypoxia, despite signaling from EGFR preventing widespread necrosis (left panel). In contrast cells with a defective MTORC1 sensor fail to adequately inhibit mTORC1 in response to nutrient deprivation or hypoxia resulting in more widespread areas of necrosis (right panel). C, scheme of mTORC1 signal transduction to S6 kinase 1 (S6 K1). S6 K1 phosphorylates both RPS6 at Ser 240/244 as well as mTOR at Ser 2448. D, survival analysis depending on Iba1 staining frequency (median split, above median: high, below and equal to median low). $P$ values were calculated using the Wilcoxon test. (TIF $559 \mathrm{~kb}$ )

\section{Acknowledgements}

The Dr. Senckenberg Institute of Neurooncology is supported by the Dr. Senckenberg Foundation and the Hertie Foundation. J.P.S. is "Hertie Professor of Neurooncology". P.S.Z. has received funding by the Frankfurt Research Funding (FFF) (program "Nachwuchswissenschaftler"). M.W.R. and P.N.H. have received a fellowship by the University Cancer Centre Frankfurt (UCT). M.W.R. has also received funding by the Frankfurt Research Funding (FFF) 'Clinician Scientists Program'. M.M. would like to thank the Luxembourg National Research Fond (FNR) for the support (FNR PEARL P16/BM/11192868 grant).

\section{Authors' contributions}

Study design and writing of the manuscript: MWR, PSZ, MM, JPS, MW, PNH. Provided material, data collection and data analyses: MWR, PSZ, MM, TP, DR CS, JPS, MW, PNH. Performed experiments: MWR, PSZ, HU, PNH. All authors read and approved the final manuscript.

\section{Competing interests}

MWR, JPS and PNH received a grant to purchase materials necessary for immunohistochemistry from Oncoscience, the pharmaceutical company that owns nimotuzumab. DR is an employee and managing director of Oncoscience.

\section{Publisher's Note}

Springer Nature remains neutral with regard to jurisdictional claims in published maps and institutional affiliations.

\section{Author details}

${ }^{1}$ Dr. Senckenberg Institute of Neurooncology, University Hospital Frankfurt, Goethe University, Schleusenweg 2-16, 60528 Frankfurt am Main, Germany. ${ }^{2}$ German Cancer Consortium (DKTK), Partner Site Frankfurt/Mainz, Frankfurt am Main, Germany. ${ }^{3}$ German Cancer Research Center (DKFZ), Heidelberg, Germany. ${ }^{4}$ Institute of Neurology (Edinger-Institute), University Hospital Frankfurt, Goethe University, Heinrich-Hoffmann-Str. 7, 60528 Frankfurt am Main, Germany. ${ }^{5}$ Luxembourg Centre for Systems Biomedicine (LCSB), University of Luxembourg, Dudelange, Luxembourg. ${ }^{6}$ Laboratoire national de santé (LNS), Dudelange, Luxembourg. ${ }^{7}$ Luxembourg Centre of Neuropathology (LCNP), Dudelange, Luxembourg. ${ }^{8}$ Department of Neuropathology, University of Bonn, Bonn, Germany. ${ }^{9}$ Oncoscience GmbH, Schenefeld, Germany. ${ }^{10}$ Department of Neurosurgery, University Hospital Frankfurt, Goethe University, Frankfurt am Main, Germany. ${ }^{11}$ Department of Neurosurgery, University Hospital Hamburg Eppendorf, Martinistrasse 52, 20246 Hamburg, Germany.

Received: 10 August 2018 Accepted: 10 August 2018

Published online: 21 August 2018

\section{References}

1. Babak S, Mason WP (2018) mTOR inhibition in glioblastoma: requiem for a dream? Neuro-oncology: noy034-noy034. https://doi.org/10.1093/neuonc/ noy034

2. Bar-Peled L, Sabatini DM (2014) Regulation of mTORC1 by amino acids. Trends Cell Biol 24:400-406. https://doi.org/10.1016/j.tcb.2014.03.003

3. Bode U, Massimino M, Bach F, Zimmermann M, Khuhlaeva E, Westphal M, Fleischhack G (2012) Nimotuzumab treatment of malignant gliomas. Expert Opin Biol Ther 12:1649-1659. https://doi.org/10.1517/14712598.2012.733367

4. Brugarolas J, Lei K, Hurley RL, Manning BD, Reiling JH, Hafen E, Witters LA, Ellisen LW, Kaelin WG Jr (2004) Regulation of mTOR function in response to hypoxia by REDD1 and the TSC1/TSC2 tumor suppressor complex. Genes Dev 18:2893-2904

5. Chiang GG, Abraham RT (2005) Phosphorylation of mammalian target of rapamycin (mTOR) at Ser-2448 is mediated by p70S6 kinase. J Biol Chem 280:25485-25490. https://doi.org/10.1074/jbc. M501707200

6. Chinnaiyan P, Won M, Wen PY, Rojiani AM, Werner-Wasik M, Shih HA, Ashby LS, Michael Yu H-H, Stieber WW, Malone SC et al (2017) A randomized phase II study of everolimus in combination with chemoradiation in newly diagnosed glioblastoma: results of NRG oncology RTOG 0913. Neurooncology: nox209-nox209. https://doi.org/10.1093/neuonc/nox209

7. Chong DQ, Toh XY, Ho IA, Sia KC, Newman JP, Yulyana Y, Ng WH, Lai SH, Ho MM, Dinesh N et al (2015) Combined treatment of Nimotuzumab and rapamycin is effective against temozolomide-resistant human gliomas regardless of the EGFR mutation status. BMC Cancer 15:255. https://doi.org/ 10.1186/s12885-015-1191-3

8. Cloughesy TF, Yoshimoto K, Nghiemphu P, Brown K, Dang J, Zhu S, Hsueh T, Chen Y, Wang W, Youngkin D et al (2008) Antitumor activity of rapamycin in a phase I trial for patients with recurrent PTEN-deficient glioblastoma. PLoS Med 5:e8

9. Combs SE, Rieken S, Wick W, Abdollahi A, von Deimling A, Debus J, Hartmann C (2011) Prognostic significance of IDH-1 and MGMT in patients with glioblastoma: one step forward, and one step back? Radiat Oncol 6: 115. https://doi.org/10.1186/1748-717X-6-115

10. Dibble CC, Elis W, Menon S, Qin W, Klekota J, Asara JM, Finan PM, Kwiatkowski DJ, Murphy LO, Manning BD (2012) TBC1D7 is a third subunit of the TSC1-TSC2 complex upstream of mTORC1. Mol Cell 47:535-546. https://doi.org/10.1016/j.molcel.2012.06.009

11. Fry DW, Kraker AJ, McMichael A, Ambroso LA, Nelson JM, Leopold WR, Connors RW, Bridges AJ (1994) A specific inhibitor of the epidermal growth factor receptor tyrosine kinase. Science 265:1093-1095

12. Gieryng A, Pszczolkowska D, Walentynowicz KA, Rajan WD, Kaminska B (2017) Immune microenvironment of gliomas. Lab Investig 97:498-518. https://doi.org/10.1038/labinvest.2017.19

13. Hanahan D, Weinberg RA (2011) Hallmarks of cancer: the next generation. Cell 144:646-674. https://doi.org/10.1016/j.cell.2011.02.013

14. Harter $P N$, Jennewein $L$, Baumgarten $P$, llina $E$, Burger MC, Thiepold $A L$, Tichy J, Zornig M, Senft C, Steinbach JP et al (2015) Immunohistochemical assessment of phosphorylated mTORC1-pathway proteins in human brain tumors. PLoS One 10:e0127123. https://doi.org/10.1371/journal.pone. 0127123

15. Hegi ME, Diserens AC, Gorlia T, Hamou MF, de Tribolet N, Weller M, Kros JM, Hainfellner JA, Mason W, Mariani L et al (2005) MGMT gene silencing and benefit from temozolomide in glioblastoma. N Engl J Med 352:997-1003

16. Hegi ME, Liu L, Herman JG, Stupp R, Wick W, Weller M, Mehta MP, Gilbert MR (2008) Correlation of O6-methylguanine methyltransferase (MGMT) promoter methylation with clinical outcomes in glioblastoma and clinical strategies to modulate MGMT activity. J Clin Oncol Off J Am Soc Clin Oncol 26:4189-4199. https://doi.org/10.1200/JCO.2007.11.5964 
17. Hockel M, Knoop C, Schlenger K, Vorndran B, Baussmann E, Mitze M Knapstein PG, Vaupel P (1993) Intratumoral pO2 predicts survival in advanced cancer of the uterine cervix. Radiother Oncol 26:45-50

18. Huang J, Yuan X, Pang Q, Zhang H, Yu J, Yang B, Zhou L, Zhang F, Liu F (2018) Radiosensitivity enhancement by combined treatment of nimotuzumab and celecoxib on nasopharyngeal carcinoma cells. Drug Des Devel Ther 12:2223-2231. https://doi.org/10.2147/DDDT.S163595

19. Inoki K, Li Y, Zhu T, Wu J, Guan KL (2002) TSC2 is phosphorylated and inhibited by Akt and suppresses mTOR signalling. Nat Cell Biol 4:648-657

20. Inoki K, Zhu T, Guan KL (2003) TSC2 mediates cellular energy response to control cell growth and survival. Cell 115:577-590

21. Kennedy BC, Showers CR, Anderson DE, Anderson L, Canoll P, Bruce JN, Anderson RC (2013) Tumor-associated macrophages in glioma: friend or foe? J Oncol 2013:486912. https://doi.org/10.1155/2013/486912

22. Kessler T, Sahm F, Sadik A, Stichel D, Hertenstein A, Reifenberger G, Zacher A, Sabel M, Tabatabai G, Steinbach J et al (2018) Molecular differences in IDH wildtype glioblastoma according to MGMT promoter methylation. Neuro-Oncology 20:367-379. https://doi.org/10.1093/neuonc/nox160

23. Kovacina KS, Park GY, Bae SS, Guzzetta AW, Schaefer E, Birnbaum MJ, Roth RA (2003) Identification of a proline-rich Akt substrate as a 14-3-3 binding partner. J Biol Chem 278:10189-10194. https://doi.org/10.1074/jbc. M210837200

24. Louis DN, Perry A, Reifenberger G, von Deimling A, Figarella-Branger D, Cavenee WK, Ohgaki H, Wiestler OD, Kleihues P, Ellison DW (2016) The 2016 World Health Organization classification of tumors of the central nervous system: a summary. Acta Neuropathol 131:803-820. https://doi.org/10.1007/ s00401-016-1545-1

25. Louis DNC, Webster K, Ohgaki H (2007) WHO classification of Tumours of the central nervous system. In: IARC WHO classification of Tumours, 4th edn World health organization, City

26. Luo W, Liu W, Hu X, Hanna M, Caravaca A, Paul SM (2015) Microglial internalization and degradation of pathological tau is enhanced by an anti-tau monoclonal antibody. Sci Rep 5:11161. https://doi.org/10.1038/srep11161

27. Mandel JJ, Yust-Katz S, Patel AJ, Cachia D, Liu D, Park M, Yuan Y, Kent TA, de Groot JF (2018) Inability of positive phase II clinical trials of investigational treatments to subsequently predict positive phase III clinical trials in glioblastoma. Neuro-Oncology 20:113-122. https://doi.org/10.1093/ neuonc/nox 144

28. Massimino $M$, Bode $U$, Biassoni $V$, Fleischhack $G$ (2011) Nimotuzumab for pediatric diffuse intrinsic pontine gliomas. Expert Opin Biol Ther 11:247-256. https://doi.org/10.1517/14712598.2011.546341

29. McBride SM, Perez DA, Polley MY, Vandenberg SR, Smith JS, Zheng S, Lamborn KR, Wiencke JK, Chang SM, Prados MD et al (2010) Activation of PI3K/mTOR pathway occurs in most adult low-grade gliomas and predicts patient survival. J Neuro-Oncol 97:33-40. https://doi.org/10.1007/s11060009-0004-4

30. Mellinghoff IK, Wang MY, Vivanco I, Haas-Kogan DA, Zhu S, Dia EQ, Lu KV, Yoshimoto K, Huang JH, Chute DJ et al (2005) Molecular determinants of the response of glioblastomas to EGFR kinase inhibitors. N Engl J Med 353 2012-2024

31. Meyuhas O (2015) Ribosomal protein S6 phosphorylation: four decades of research. Int Rev Cell Mol Biol 320:41-73. https://doi.org/10.1016/bs.ircmb. 2015.07.006

32. Network TCGAR (2008) Comprehensive genomic characterization defines human glioblastoma genes and core pathways. Nature 455:1061-1068

33. Ostrom QT, Gittleman H, Liao P, Rouse C, Chen Y, Dowling J, Wolinsky Y, Kruchko C, Barnholtz-Sloan J (2014) CBTRUS statistical report: primary brain and central nervous system tumors diagnosed in the United States in 2007-2011. Neuro-oncology 16(Suppl 4):iv1-i63. https://doi.org/10.1093/ neuonc/nou223

34. Pende M, Um SH, Mieulet V, Sticker M, Goss VL, Mestan J, Mueller M, Fumagalli S, Kozma SC, Thomas G (2004) S6K1(-/-)/S6K2(-/-) mice exhibit perinatal lethality and rapamycin-sensitive 5 '-terminal oligopyrimidine mRNA translation and reveal a mitogen-activated protein kinase-dependent S6 kinase pathway. Mol Cell Biol 24:3112-3124

35. Phillips AC, Boghaert ER, Vaidya KS, Mitten MJ, Norvell S, Falls HD, DeVries PJ, Cheng D, Meulbroek JA, Buchanan FG et al (2016) ABT-414, an antibodydrug conjugate targeting a tumor-selective EGFR epitope. Mol Cancer Ther 15:661-669. https://doi.org/10.1158/1535-7163.MCT-15-0901

36. Poon CC, Sarkar S, Yong WW, Kelly JJP (2017) Glioblastoma-associated microglia and macrophages: targets for therapies to improve prognosis. Brain J Neurol 140:1548-1560. https://doi.org/10.1093/brain/aww355
37. Qu YY, Hu SL, Xu XY, Wang RZ, Yu HY, Xu JY, Chen L, Dong GL (2013) Nimotuzumab enhances the radiosensitivity of cancer cells in vitro by inhibiting radiation-induced DNA damage repair. PLoS One 8:e70727. https://doi.org/10.1371/journal.pone.0070727

38. Ronellenfitsch MW, Brucker DP, Burger MC, Wolking S, Tritschler F, Rieger J, Wick W, Weller M, Steinbach JP (2009) Antagonism of the mammalian target of rapamycin selectively mediates metabolic effects of epidermal growth factor receptor inhibition and protects human malignant glioma cells from hypoxia-induced cell death. Brain 132:1509-1522

39. Ronellenfitsch MW, Steinbach JP, Wick W (2010) Epidermal growth factor receptor and mammalian target of rapamycin as therapeutic targets in malignant glioma: current clinical status and perspectives. Target Oncol 5: 183-191

40. Sancak Y, Bar-Peled L, Zoncu R, Markhard AL, Nada S, Sabatini DM (2010) Ragulator-rag complex targets $\mathrm{MTORC} 1$ to the lysosomal surface and is necessary for its activation by amino acids. Cell 141:290-303. https://doi.org/ 10.1016/j.cell.2010.02.024

41. Sancak Y, Thoreen CC, Peterson TR, Lindquist RA, Kang SA, Spooner E, Carr SA, Sabatini DM (2007) PRAS40 is an insulin-regulated inhibitor of the mTORC1 protein kinase. Mol Cell 25:903-915. https://doi.org/10.1016/j. molcel.2007.03.003

42. Semenza GL (2013) HIF-1 mediates metabolic responses to intratumoral hypoxia and oncogenic mutations. J Clin Invest 123:3664-3671. https://doi. org/10.1172/JCl67230

43. Shinojima N, Tada K, Shiraishi S, Kamiryo T, Kochi M, Nakamura H, Makino K, Saya H, Hirano H, Kuratsu J et al (2003) Prognostic value of epidermal growth factor receptor in patients with glioblastoma multiforme. Cancer Res 63:6962-6970

44. Sorensen MD, Dahlrot RH, Boldt HB, Hansen S, Kristensen BW (2018) Tumour-associated microglia/macrophages predict poor prognosis in highgrade gliomas and correlate with an aggressive tumour subtype. Neuropathol Appl Neurobiol 44:185-206. https://doi.org/10.1111/nan.12428

45. Steinbach JP, Klumpp A, Wolburg H, Weller M (2004) Inhibition of epidermal growth factor receptor signaling protects human malignant glioma cells from hypoxia-induced cell death. Cancer Res 64:1575-1578

46. Stupp R, Hegi ME, Mason WP, van den Bent MJ, Taphoorn MJ, Janzer RC, Ludwin SK, Allgeier A, Fisher B, Belanger K et al (2009) Effects of radiotherapy with concomitant and adjuvant temozolomide versus radiotherapy alone on survival in glioblastoma in a randomised phase III study: 5-year analysis of the EORTC-NCIC trial. Lancet Oncol 10:459-466. https://doi.org/10.1016/S1470-2045(09)70025-7

47. Stupp R, Mason WP, van den Bent MJ, Weller M, Fisher B, Taphoorn MJ, Belanger K, Brandes AA, Marosi C, Bogdahn U et al (2005) Radiotherapy plus concomitant and adjuvant temozolomide for glioblastoma. N Engl J Med 352:987-996

48. Talavera A, Friemann R, Gomez-Puerta S, Martinez-Fleites C, Garrido G, Rabasa A, Lopez-Requena A, Pupo A, Johansen RF, Sanchez O et al (2009) Nimotuzumab, an antitumor antibody that targets the epidermal growth factor receptor, blocks ligand binding while permitting the active receptor conformation. Cancer Res 69:5851-5859. https://doi.org/10.1158/0008-5472. CAN-08-4518

49. Testa JR, Tsichlis PN (2005) AKT signaling in normal and malignant cells. Oncogene 24:7391-7393. https://doi.org/10.1038/sj.onc.1209100

50. Thiepold AL, Lorenz NI, Foltyn M, Engel AL, Dive I, Urban H, Heller S, Bruns I, Hofmann U, Drose S et al (2017) Mammalian target of rapamycin complex 1 activation sensitizes human glioma cells to hypoxia-induced cell death. Brain J Neurol 140:2623-2638. https://doi.org/10.1093/brain/awx196

51. van den Bent M, Gan HK, Lassman AB, Kumthekar P, Merrell R, Butowski N, Lwin Z, Mikkelsen T, Nabors LB, Papadopoulos KP et al (2017) Efficacy of depatuxizumab mafodotin (ABT-414) monotherapy in patients with EGFRamplified, recurrent glioblastoma: results from a multi-center, international study. Cancer Chemother Pharmacol 80:1209-1217. https://doi.org/10.1007/ s00280-017-3451-1

52. van den Bent MJ, Brandes AA, Rampling R, Kouwenhoven MC, Kros JM, Carpentier AF, Clement PM, Frenay M, Campone M, Baurain JF et al (2009) Randomized phase II trial of erlotinib versus temozolomide or carmustine in recurrent glioblastoma: EORTC brain tumor group study 26034. J Clin Oncol 27:1268-1274

53. Weller M, Butowski N, Tran DD, Recht LD, Lim M, Hirte H, Ashby L, Mechtler L, Goldlust SA, Iwamoto F et al (2017) Rindopepimut with temozolomide for patients with newly diagnosed, EGFRvIll-expressing glioblastoma (ACT IV): a 
randomised, double-blind, international phase 3 trial. Lancet Oncol 18:13731385. https://doi.org/10.1016/S1470-2045(17)30517-X

54. Weller M, Kaulich K, Hentschel B, Felsberg J, Gramatzki D, Pietsch T, Simon M, Westphal M, Schackert G, Tonn JC et al (2014) Assessment and prognostic significance of the epidermal growth factor receptor vill mutation in glioblastoma patients treated with concurrent and adjuvant temozolomide radiochemotherapy. Int J Cancer 134:2437-2447. https://doi. org/10.1002/ijc.28576

55. Westphal M, Heese O, Steinbach JP, Schnell O, Schackert G, Mehdorn M, Schulz D, Simon M, Schlegel U, Senft C et al (2015) A randomised, open label phase III trial with nimotuzumab, an anti-epidermal growth factor receptor monoclonal antibody in the treatment of newly diagnosed adult glioblastoma. Eur J Cancer. https://doi.org/10.1016/j.ejca.2014.12.019

56. Wick W, Gorlia T, Bady P, Platten M, van den Bent MJ, Taphoorn MJ, Steuve J, Brandes AA, Hamou MF, Wick A et al (2016) Phase II study of radiotherapy and Temsirolimus versus Radiochemotherapy with Temozolomide in patients with newly diagnosed glioblastoma without MGMT promoter Hypermethylation (EORTC 26082). Clin Cancer Res 22:4797-4806. https://doi. org/10.1158/1078-0432.CCR-15-3153

57. Wolff JE, Rytting ME, Vats $T S$, Zage PE, Ater JL, Woo S, Kuttesch J, Ketonen L, Mahajan A (2012) Treatment of recurrent diffuse intrinsic pontine glioma: the MD Anderson Cancer Center experience. J Neuro-Oncol 106:391-397. https://doi.org/10.1007/s1 1060-011-0677-3

58. Zeiner PS, Preusse C, Blank AE, Zachskorn C, Baumgarten P, Caspary L, Braczynski AK, Weissenberger J, Bratzke H, Reiss S et al (2015) MIF receptor CD74 is restricted to microglia/macrophages, associated with a M1polarized immune milieu and prolonged patient survival in gliomas. Brain Pathol 25:491-504. https://doi.org/10.1111/bpa.12194

Ready to submit your research? Choose BMC and benefit from:

- fast, convenient online submission

- thorough peer review by experienced researchers in your field

- rapid publication on acceptance

- support for research data, including large and complex data types

- gold Open Access which fosters wider collaboration and increased citations

- maximum visibility for your research: over $100 \mathrm{M}$ website views per year

At BMC, research is always in progress.

Learn more biomedcentral.com/submissions 